\title{
Fatigue of extremely fine bainite
}

\author{
M. J. Peet ${ }^{* 1}$, P. Hill ${ }^{2}$, M. Rawson ${ }^{2}$, S. Wood ${ }^{2}$ and H. K. D. H. Bhadeshia ${ }^{1}$
}

There is a novel steel invented in which the structure consists of extremely fine platelets of bainitic ferrite dispersed in a matrix of carbon enriched retained austenite. The resulting large density of interfaces makes the alloy very strong in its transformed condition. The authors report the first fatigue tests on this system, by measuring the life of parallel gauged samples tested using cyclic loading in tension, with maximum stresses in the range 1.2-1.6 GPa. A comparison of the results against published data indicates that the performance of the steel is consistent with the behaviour of other strong steels, in spite of the fact that it is produced using an air melting technique.

Keywords: Fatigue, Bainite, Nanostructure, Inclusions, Retained austenite

\section{Introduction}

It is now possible to routinely and cheaply generate a very high density of interfaces in steel, resulting in strength which can be controlled in the range 1.6-2.5 GPa with a hardness of about $650-700 \mathrm{HV}$, depending on the transformation conditions. The structure, which is obtained by the solid state transformation of austenite at low homologous temperatures $\left(180-250^{\circ} \mathrm{C}\right)$, consists of plates of bainitic ferrite, which are just $20-40 \mathrm{~nm}$ in thickness, dispersed in a residue of carbon enriched retained austenite (Fig. 1). ${ }^{1,2}$

There is an interest in developing these steels for the manufacture of shafts, which have a high surface integrity but which are subjected during rotation to alternating stresses, making the fatigue performance of the material an important design parameter. The purpose of the present work was to determine, for the first time, the fatigue behaviour of the nanostructured steel.

\section{Methods}

There are many variants of the alloy system that have been shown to be capable of producing the bainite described above; the one which is the focus of the present work contains a modest addition of cobalt in order to accelerate the transformation, since cobalt increases the free energy difference between austenite and ferrite. ${ }^{3,4}$ The material used was produced as a $25 \mathrm{~kg}$ experimental air melt supplied by Corus (London, UK), rolled to $\sim 45 \mathrm{~mm}$ thick plate. A block $40 \times 50 \times 100 \mathrm{~mm}$ was homogenised in a vacuum furnace at $1200^{\circ} \mathrm{C}$ for 2 days, followed by furnace cooling to room temperature. The chemical composition of the alloy is

$$
\begin{aligned}
& \mathrm{Fe}-0.80 \mathrm{C}-1.59 \mathrm{Si}-2.01 \mathrm{Mn}-1.00 \mathrm{Cr}-0.24 \mathrm{Mo} \\
& -1.51 \mathrm{Co}-0.002 \mathrm{P}-0.002 \mathrm{~S}(\mathrm{wt}-\%)
\end{aligned}
$$

\footnotetext{
${ }^{1}$ Department of Materials Science and Metallurgy, Cambridge CB2 3QZ, UK

${ }^{2}$ Rolls-Royce plc, Derby, UK

*Corresponding author, email mjp54@cam.ac.uk
}

The structure and tensile properties of this alloy have been characterised previously. Austenitisation for $30 \mathrm{~min}$ at $900^{\circ} \mathrm{C}$ followed by isothermal transformation at $200^{\circ} \mathrm{C}$ for 9 days yields a bainitic-ferrite volume fraction of 0.79 and a bainite plate thickness of $38 \pm 2 \mathrm{~nm}$ resulting in hardness of $690 \mathrm{HV}^{5,6}$ The proof and tensile strengths reported were 1.45 and $2 \cdot 2 \mathrm{GPa}$ respectively, with an elongation of $5 \%$ and a fracture toughness of $28 \mathrm{MPa} \mathrm{m}^{-1 / 2}$. In a separate work $^{7}$ where the transformation period at $200^{\circ} \mathrm{C}$ was 3 days, the $0 \cdot 2 \%$ proof strength achieved was $1 \cdot 19 \mathrm{GPa}$, ultimate tensile strength was $2 \cdot 18 \mathrm{GPa}$ and elongation was $4 \cdot 6 \%$.

Cylinders of $10 \mathrm{~mm}$ in diameter, machined from the homogenised steel, were placed in a furnace at $500^{\circ} \mathrm{C}$; the furnace was purged with argon throughout the heat treatment. The temperature was then raised to $900^{\circ} \mathrm{C}$ over a period of $30 \mathrm{~min}$ and held at that temperature for $15 \mathrm{~min}$, after which the samples were transferred into an oven at $200 \pm 0 \cdot 1{ }^{\circ} \mathrm{C}$ for 10 days to generate the fine bainite with a hardness of $680 \pm 3$ HV50. After heat treatment, the blanks were machined into push-pull type fatigue samples with the final dimensions of $4.5 \mathrm{~mm}$ diameter, $12 \mathrm{~mm}$ gauge length and a $9 \mathrm{~mm}$ radius, leading on to the grips which had 20 unified fine threads. Such samples expose a greater volume of material to tensile stress than rotating bend specimens and, hence, are better able to discover the role of inclusions. The gauge length was polished to give a $0 \cdot 25 \mu \mathrm{m}$ finish. The gauge length was masked, and the threads of the samples were shot peened using glass beads in order to prevent failure in the specimen grips.

Fatigue testing was conducted on an Instron 8800 testing machine, controlled by Instron LCF v7.2 Fast Track 2 software. The loading was at a frequency of $0.25 \mathrm{~Hz}$, with each $4 \mathrm{~s}$ cycle consisting of four steps, each of $1 \mathrm{~s}$ duration: a hold at the minimum tensile stress, followed by a linear ramp to the maximum stress, hold at that stress and a ramp down to the minimum stress. This is often said to be a trapezoidal 1-1-1-1 s profile. The ratio of the minimum to maximum stress was maintained at $R=0 \cdot 1$. 


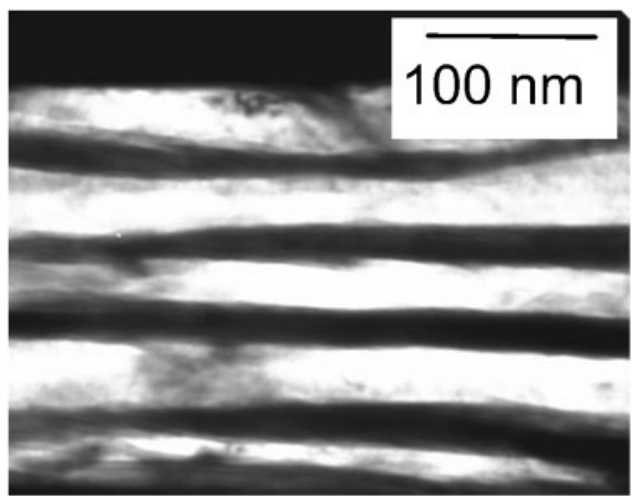

1 Transmission electron micrograph showing fine plates of bainite in alloy studied here following transformation at $200^{\circ} \mathrm{C}$ for 3 days: darker regions represent intervening austenite (courtesy of C. Garcia-Mateo)

\section{Results}

Figure 2 summarises the outcomes and compares against the previously reported tensile strength; ${ }^{5,6}$ the $0 \cdot 2 \%$ proof strength and elongation were reported as $1.45 \mathrm{MPa}$ and $4 \cdot 6 \%$ respectively.

Fractography revealed that failure initiated from inclusions except for samples tested at the highest of stresses, where cracks apparently began from the polished surface. The origins of fracture can be seen in Figs. 3-7, and the complete set of results is summarised in Table 1. The inclusions were identified using energy dispersive X-ray analysis as oxides, high in aluminium or magnesium; calcium sulphide was also observed.

Classic 'white area' or 'fish eye' fracture patterns characteristic of fatigue fracture ${ }^{8}$ can be seen in samples tested at maximum stresses $\sigma_{\max }$ of 1.3 and $1.4 \mathrm{GPa}$ in Figs. 3 and 6. For the samples tested at $\sigma_{\max }=1 \cdot 5$ and $1 \cdot 6 \mathrm{GPa}$, the fracture surfaces appeared much more brittle, making it very difficult to discern any area of fatigue crack growth.

The results are summarised as an $\mathrm{S}-\mathrm{N}$ curve in Fig. 2. Regression analysis of the data, excluding the samples tested again at the greatest stress (i.e. excluding the filled

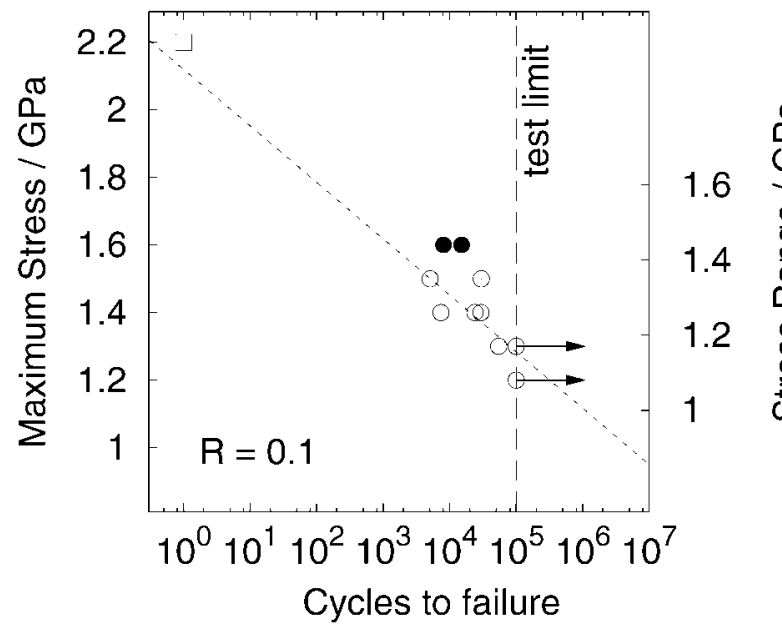

2 Fatigue life as function of stress range: single square is tensile test result, ${ }^{5,6}$ circles are fatigue data and filled circles represent samples, which previously survived $10^{5}$ cycles at lower stress but did not fail (arrowed points)

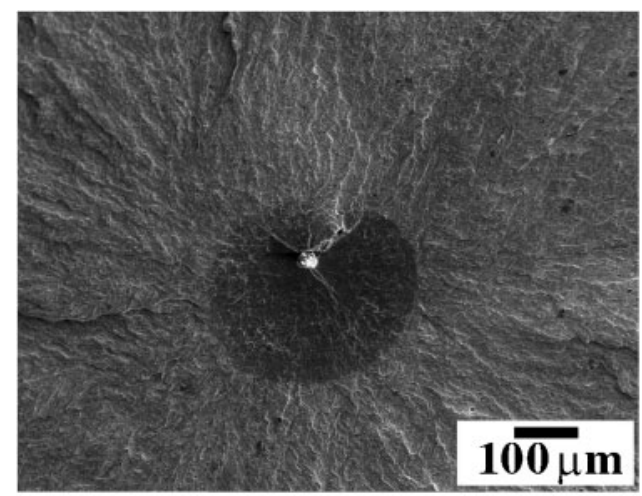

3 F3, 1.3 GPa (52 460 cycles), fracture initiation from centre of sample: inclusion is identified as alumina

circles in Fig. 2), permitted the estimation of the fatigue life as defined for the authors' purposes to be the maximum cyclic stress for which the samples must survive $10^{7}$ cycles: this stress was found to be $\sigma_{\max }=855 \mathrm{MPa}$, which may represent a conservative estimate given that two of the samples survived $10^{5}$ cycles at 1.2 and $1.3 \mathrm{GPa}$ without failure.

A strong correlation has been observed between the fatigue limit and the hardness over a range of steels and microstructures $^{9,10}$ (Fig. 8). The linear trend in their results breaks down at high hardness values, with a maximum fatigue limit of $900 \mathrm{MPa}$ at hardness of $\sim 600 \mathrm{HV}$. The linear relation between the fatigue limit and hardness has also been shown for values below $400 \mathrm{HV}$, independent of microstructure or steel type. ${ }^{11}$ This might be expected, given that the resistance to plastic deformation, as measured by hardness indentations, determines also the resistance to the plasticity required to initiate and propagate fatigue. ${ }^{11}$ Fatigue data analysed by Murakami ${ }^{12}$ led to the proposal of a 'defect free fatigue limit' $\sigma_{\mathrm{w} 0}$, which can be calculated from the tensile strength $\sigma_{\mathrm{U}}$ or the hardness (HV)

$$
\sigma_{\mathrm{w} 0} \cong 0 \cdot 5 \sigma_{\mathrm{U}} \cong 1 \cdot 6 \mathrm{HV} \quad \mathrm{MPa}
$$

This relationship has been shown to work well for hardness values below $\sim 400 \mathrm{HV}$, independent of microstructure and even for aluminium alloys. However, L'vov et al. $^{13}$ studied a steel which contained metastable austenite and concluded that the microstructure did have an influence, both through the austenite substructure resulting from warm deformation during processing, and

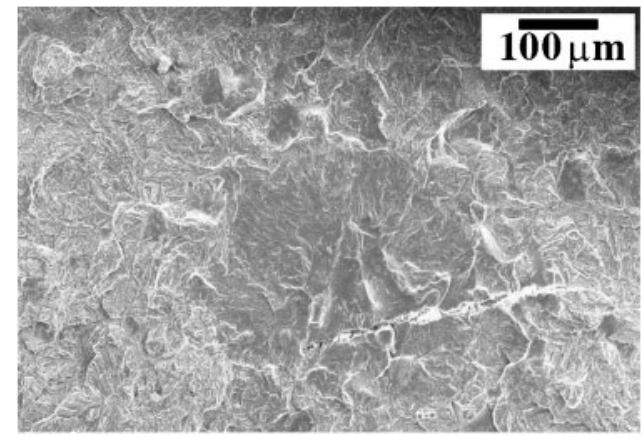

4 F4, 1.4 GPa (7400 cycles), circular fatigue crack which grew from string of inclusions before onset of gross fracture 


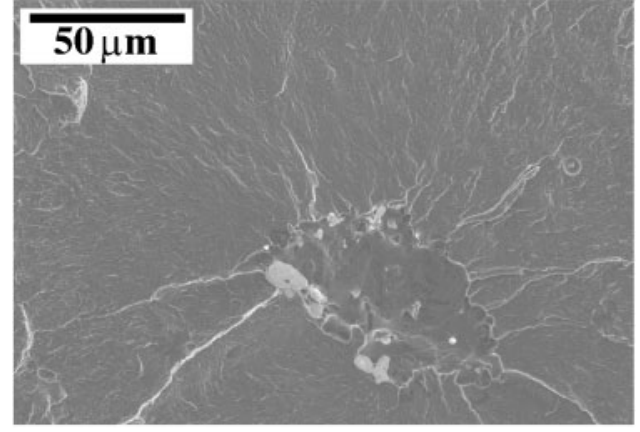

5 F5, 1.4 GPa (29 627 cycles), irregularly shaped cluster of inclusions

by transformation to martensite during loading. It is possible that both of these would be reflected in increased ultimate tensile strength and hardness.

Figure 8 shows that the present steel, consisting of fine bainite and retained austenite, has a high fatigue limit, which compares well with the other data. ${ }^{9,10}$ On the basis of equation (1), the present alloy should have a 'defect free' fatigue limit of $\sigma_{\mathrm{w} 0}=1 \cdot 1 \mathrm{GPa}$.

Given that the fatigue limit correlates with the hardness, which is a coarse measure of properties, it is not possible from the present work to isolate the specific influence of retained austenite. Wenyan et al. ${ }^{14}$ studied carbide free bainitic steel samples containing retained austenite fractions $0 \cdot 08-0 \cdot 23$ and found that the threshold stress intensity increased and the crack propagation rate decreased, as the fraction of retained austenite was increased. This is in spite of the fact that the samples with less austenite were stronger. In general, the opposite effect is expected since the crack growth increment per cycle should be inversely proportional to the cyclic yield strength because the crack tip opening displacement will be smaller when the yield strength is large. This reinforces the conclusion ${ }^{14}$ that the austenite is beneficial to fatigue performance. Although the detailed mechanism is not understood, it is possible that the stress or strain induced transformation of austenite

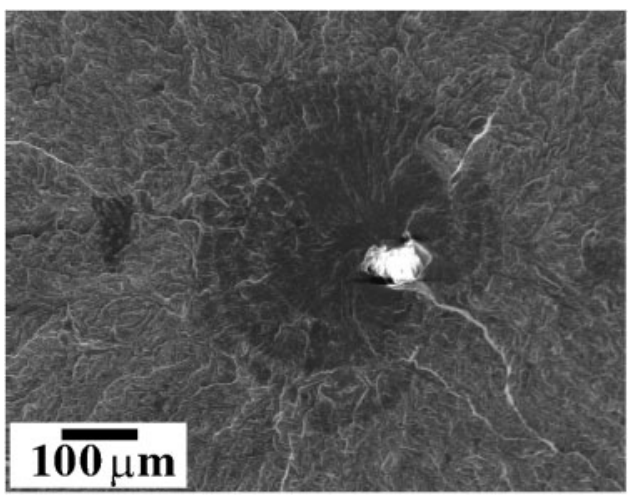

6 F6, 1.4 GPa, fracture surface, showing river lines leading to initiation site and illustrating size of inclusion, which is likely to be $\mathrm{MgO}$, as indicated by microanalysis

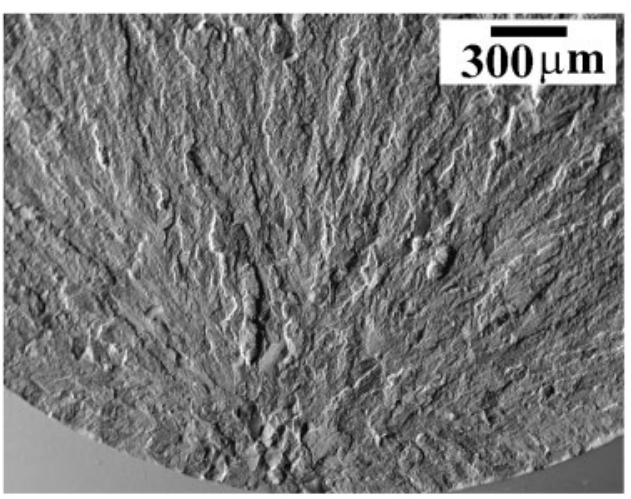

$7 \mathrm{F7}, 1.5 \mathrm{GPa}$, fracture initiated at or in close proximity of surface, with no inclusion identified as culprit

is responsible for the improved properties. ${ }^{15}$ On the other hand, a high strain hardening rate accompanying the transformation of austenite may be detrimental if this reduces the ability of the material to accommodate plastic strain. ${ }^{16,17}$ The role of austenite therefore deserves further study.

Table 1 Fatigue test data, loading in tension with $R=0.1$, trapezoidal loading profile (1-1-1-1) with $0.25 \mathrm{~Hz}$ : $\sigma_{\max }$ represents maximum stress, $d$ is depth at which an initiating inclusion is found below sample surface and $\sigma_{\mathrm{L}}$ is estimated fatigue limit; 'GL' stands for gauge length

\begin{tabular}{|c|c|c|c|c|c|c|c|}
\hline $\begin{array}{l}\sigma_{\max } \\
\mathrm{GPa}\end{array}$ & Cycles & Identification & Inclusion & $d, \mu \mathrm{m}$ & Inclusion size & Fatigue zone size & $\begin{array}{l}\sigma_{\mathrm{L}} \\
\mathrm{MPa}\end{array}$ \\
\hline $1 \cdot 2$ & $>10^{5}$ & $\mathrm{~F} 1$ & $\ldots$ & $\ldots$ & $\ldots$ & $\ldots$ & $\ldots$ \\
\hline $1 \cdot 3$ & $>10^{5}$ & F2 & $\ldots$ & $\ldots$ & $\ldots$ & $\ldots$ & $\ldots$ \\
\hline $1 \cdot 3$ & 52460 & F3, Fig. 3 & $\mathrm{O}, \mathrm{Al}, \mathrm{Cr}$ & 1400 & $\begin{array}{l}30-40 \mu \mathrm{m} \text { diameter sphere, secondary } \\
\text { inclusion is string } 200 \times 20 \mu \mathrm{m}\end{array}$ & $220 \mu \mathrm{m}$ diameter disk & 710 \\
\hline $1 \cdot 4$ & 7400 & F4, Fig. 4 & $\mathrm{Al}, \mathrm{Mg}, \mathrm{O}, \mathrm{CaS}$ & 1070 & $300 \mu \mathrm{m}$ long cluster/string & $300 \mu \mathrm{m}$ diameter disk & 612 \\
\hline $1 \cdot 4$ & 29627 & F5, Fig. 5 & $\mathrm{Al}, \mathrm{O}$ & 110 & $\begin{array}{l}\text { Cluster of inclusions } 10-20 \mu \mathrm{m} \text {, } \\
\text { string of particles } 60 \mu \mathrm{m} \text { in length }\end{array}$ & $60 \times 80 \mu \mathrm{m}^{2}$ & 699 \\
\hline $1 \cdot 4$ & 23932 & F6, Fig. 6 & $\mathrm{MgO}$ & 1125 & $50 \mu \mathrm{m}$ sphere & $\begin{array}{l}275-400 \mu \mathrm{m}, \text { concentric } \\
\text { rings, final of which is } \\
400 \mu \mathrm{m}\end{array}$ & 673 \\
\hline $1 \cdot 5$ & 5088 & F7, Fig. 7 & & & $\begin{array}{l}\text { Initiated at surface, with } \\
\text { brittle/granular fracture }\end{array}$ & & \\
\hline 1.5 & 29817 & F8 & $\mathrm{Mg}, \mathrm{Al}, \mathrm{O}, \mathrm{Ca}, \mathrm{S}$ & 80 & $\begin{array}{l}\text { Initiated close to surface, flat } \\
\text { appearance/possibly by fatigue }\end{array}$ & $\begin{array}{l}\text { 30-50 } \mu \mathrm{m} \text { surface } \\
\text { hemisphere }\end{array}$ & \\
\hline $1 \cdot 6$ & 15131 & F9 & & 0 & $\begin{array}{l}\text { Initiated at surface, with } \\
\text { brittle/granular fracture }\end{array}$ & $\cdots$ & \\
\hline $1 \cdot 6$ & 8047 & F10 & & 0 & $\begin{array}{l}\text { Non-GL failure (threads), complex } \\
\text { fracture surface, multiple possible } \\
\text { initiation points at surface }\end{array}$ & $\ldots$ & \\
\hline
\end{tabular}




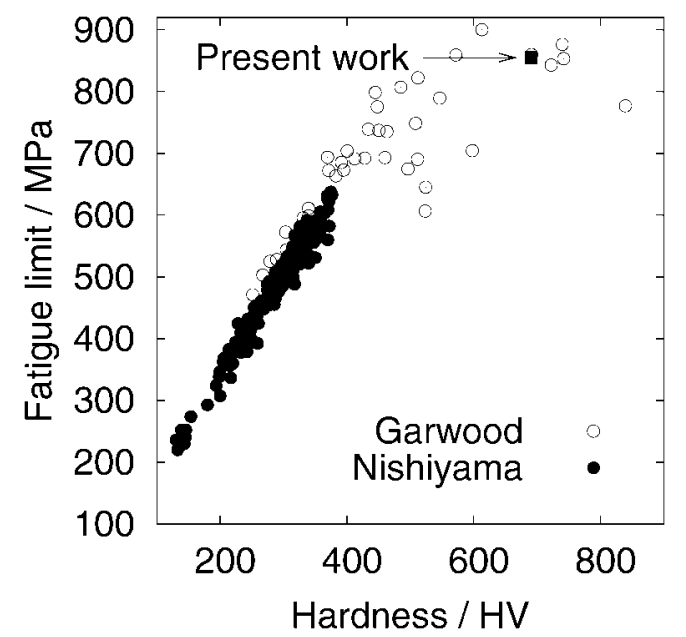

8 Correlation of fatigue life with hardness; data represented by black dots are due to previous studies ${ }^{9,10}$ for variety of steels in normalised and quenched and tempered conditions: in some cases, reported Rockwell hardness (C scale) values have been converted to Vickers hardness using empirical equation ${ }^{21}$

The level of cleanliness with respect to non-metallic inclusions has naturally been correlated against fatigue performance by many researchers. However, the problem is difficult since the occurrence of infrequent and large inclusions depends also on the volume sampled by the stress. Inclusions in general may be regarded as stress concentrations through a variety of mechanisms, including the loss of coherence with the matrix and when the particle itself fractures and introduces a sharp crack. The inclusion size, approximate shape and position within the sample are recorded in Table 1. It has been proposed $^{18,19}$ that the fatigue limit $\sigma_{\mathrm{L}}$ is related to the hardness and effective area of the inclusion as follows

$$
\sigma_{\mathrm{L}}=\frac{M\left(H_{\mathrm{V}}+120\right)}{\left[\text { area }^{2}\right]^{1 / 6}}
$$

where $M$ is a constant depending on the position of a crack, non-metallic inclusion or defect, and is set equal to 1.43 for surface defects, 1.41 for subsurface defects which touch the surface and 1.56 for internal defects. The fatigue limit estimated in this way for each sample, based on the observed size of the inclusion, is appended to Table 1. There is some consistency in that the sample with the lowest life during testing with $\sigma_{\max }=1.4 \mathrm{GPa}$ also has the lowest calculated $\sigma_{\mathrm{L}}$. Based on equation (2), the expected fatigue limit is $600-700 \mathrm{MPa}$ depending on the inclusions sizes observed. Given that the fatigue limit obtained by extrapolating the data in Fig. 2 is $855 \mathrm{MPa}$, it is speculated that the steel is more tolerant to inclusions, possibly because of the presence of the retained austenite, which would tend to relieve stress concentrations via transformation induced plasticity. ${ }^{20}$

\section{Conclusions}

A nanostructured steel containing slender plates of bainitic ferrite in a matrix of high carbon retained austenite has been studied under fatigue loading using tensile specimens in order to uniformly stress a significant volume of material. The tests were performed at high stresses whose maximum values were between
1.2 and $1.6 \mathrm{GPa}$. The performance of the steel is generally consistent with published work on iron alloys of similar hardness. A fatigue limit of $\sim 855 \mathrm{MPa}$ is estimated assuming no failure in $10^{7}$ cycles, based on extrapolation of data in which the maximum number of cycles permitted was $10^{5}$. Samples tested at lower loads survived $10^{5}$ cycles, which possibly makes the extrapolation a conservative estimate of the fatigue limit.

As is well known, the fatigue life depends upon the cleanliness of the steel, which, in the present work, was made as an air melt. It is assumed therefore that the fatigue performance of the nanostructured steel should be better when it is manufactured using clean steelmaking technologies.

\section{Acknowledgements}

The authors are grateful to Rolls-Royce plc for funding this research and to Professor L. Greer for the provision of laboratory facilities at the University of Cambridge.

\section{References}

1. F. G. Caballero, H. K. D. H. Bhadeshia, K. J. A. Mawella, D. G. Jones and P. Brown: 'Very strong, low-temperature bainite', Mater. Sci. Technol., 2002, 18, 279-284.

2. F. G. Caballero and H. K. D. H. Bhadeshia: 'Very strong bainite', Curr. Opin. Solid State Mater. Sci., 2004, 8, 251-257.

3. H. I. Aaronson, H. A. Domian and G. M. Pound: 'Partitioning of alloying elements between austenite and proeutectoid ferrite and bainite', Trans. TMS-AIME, 1966, 236, 781-796.

4. C. Garcia-Mateo, F. G. Caballero and H. K. D. H. Bhadeshia: 'Acceleration of low-temperature bainite', ISIJ Int., 2003, 43, 18211825.

5. C. Garcia-Mateo and F. G. Caballero: 'Role of retained austenite on tensile properties of steels with bainitic microstructures', Mater. Trans., 2005, 46, 1839-1846.

6. C. Garcia-Mateo, F. G. Caballero and H. K. D. H. Bhadeshia: 'Mechanical properties of low-temperature bainite', Mater. Sci. Forum, 2005, 500-501, 495-502.

7. M. Y. Sherif: 'Characterisation and development of nanostructured, ultrahigh strength, and ductile bainitic steels'; 2005, Cambridge, University of Cambridge.

8. P. H. Frith: 'Fatigue tests on rolled alloy steels mad in electric and open-hearth furnaces', J. Iron Steel Inst., 1955, 180, 26-33.

9. M. F. Garwood, H. H. Zurburg and M. A. Erickson: 'Interpretation of tests and correlation with service', in 'Correlation of laboratory tests and service performance', 1-77; 1951, Philadelphia, PA, ASM International.

10. S. Nishiyama: 'Statistical analysis of fatigue test data', J. Soc. Mater. Sci. Jpn, 1980, 29, 24-29.

11. G. Chalant and B. M. Suyitno: 'Effects of microstructure on low and high cycle fatigue behaviour of a micro-alloyed steel', in Proc. 6th Int. Conf. on 'Mechical behaviour of materials', (ed. M. Jono and T. Inoue), Vol. 6, 511-516; 1991, Oxford, Elsevier Science.

12. Y. Murakami: 'Metal fatigue: effects of small defects and nonmetallic inclusions'; 2002, Oxford, Elsevier Science.

13. Yu. B. L'vov, A. Ya. Maloletnev, M. D. Perkas, Yu. G. Birakhovskii, N. K. Leonova and Y. B. Gurevich: 'Features of the fatigue failure of steel with metastable austenite', Met. Sci. Heat Treat., 1980, 22, 868-870.

14. L. Wenyan, Q. Jingxin and S. Hesheng: 'Fatigue crack growth behaviour of a $\mathrm{Si}-\mathrm{Mn}$ steel with carbide-free lathy bainite', J. Mater. Sci., 1997, 32, 427-430.

15. G. R. Chanani, S. D. Antolovich and W. W. Gerberich: 'Fatigue crack propagation in TRIP steels', Metall. Trans., 1972, 3, 26612672.

16. B. Cotterell: 'An interpretation of the mechanics of crack growth by fatigue', Trans. ASME, 1965, 87, 230-236.

17. Z. Khan and M. Ahmed: 'Stress-induced martensitic transformation in metastable austenitic stainless steels: effect on fatigue crack growth rate', J. Mater. Eng. Perform., 1996, 5, 201-208.

18. Y. Murakami, S. Kodama and S. Konuma: 'Quantitative equation of effects of non-metallic inclusions on fatigue strength of metals', Trans. Jpn Soc. Mech. Eng. A, 1988, 54A, 688-696. 
19. Y. Murakami and H. Usuki: 'Prediction on fatigue strength of high-strength steels based on statistical evaluation of inclusion size', Trans. Jpn Soc. Mech. Eng. A, 1989, 55A, 213-221.

20. W. W. Gerberich, G. Thomas, E. R. Parker and V. F. Zackay: 'Metastable austenites: decomposition and strength', in Proc. 2nd
Int. Conf. on 'Strength of metals and alloys', 894-899; 1970, Metals Park, OH, ASM International.

21. H. Qvarnström: 'Technical note: a mathematical formula for transformation between the steel hardness scales of Rockwell $\mathrm{C}$ and Vickers', J. Heat Treat., 1989, 7, 65-67. 